Contract No. and Disclaimer:

This manuscript has been authored by Savannah River Nuclear Solutions, LLC under Contract No. DE-AC09-08SR22470 with the U.S. Department of Energy. The United States Government retains and the publisher, by accepting this article for publication, acknowledges that the United States Government retains a non-exclusive, paid-up, irrevocable, worldwide license to publish or reproduce the published form of this work, or allow others to do so, for United States Government purposes. 


\title{
VERTICAL MIGRATION OF RADIONUCLIDES IN THE VICINITY OF THE CHERNOBYL CONFINEMENT SHELTER
}

\author{
Mikhail D. Bondarkov, ${ }^{*}$ Viktor A. Zheltonozhsky, ${ }^{\dagger}$ Maryna V. Zheltonozhskaya, ${ }^{\dagger}$ \\ Nadezhda V. Kulich, ${ }^{\dagger}$ Andrey M. Maksimenko, ${ }^{*}$ Eduardo B. Farfán, ${ }^{\ddagger}$ G.Timothy \\ Jannik, ${ }^{\ddagger}$ and James C. Marra ${ }^{\ddagger}$ \\ * Chernobyl Center for Nuclear Safety, Radioactive Waste and Radioecology, \\ International Radioecology Laboratory, 07100, Slavutych, Ukraine \\ ${ }^{\dagger}$ Institute of Nuclear Research of the National Academy of Sciences of Ukraine, Kyiv \\ 03680, Ukraine \\ ${ }^{\ddagger}$ Savannah River National Laboratory, Aiken, SC 29808, USA
}

\section{For reprints and correspondence contact:}

Eduardo B. Farfán, Ph.D.

Environmental Science and Biotechnology

Environmental Analysis Section

Savannah River National Laboratory

Savannah River Nuclear Solutions, LLC

773-42A, Room 236

Aiken, SC 29808

E-mail: Eduardo.Farfan@srnl.doe.gov

Phone: (803) 725-2257, Fax: (803) 725-7673

\section{Part of the Savannah River National Laboratory HPJ Special Issue}

October 2011 


\begin{abstract}
Studies on vertical migration of Chernobyl-origin radionuclides in the $5-\mathrm{km}$ zone of the Chernobyl Nuclear Power Plant (ChNPP) in the area of the Red Forest experimental site were completed. Measurements were made by gamma spectrometric methods using high purity germanium (HPGe) detectors with beryllium windows. Alpha-emitting isotopes of plutonium were determined by the measurement of the x-rays from their uranium progeny. The presence of ${ }^{60} \mathrm{Co},{ }^{134,137} \mathrm{Cs},{ }^{154,155} \mathrm{Eu}$, and ${ }^{241} \mathrm{Am}$ in all soil layers down to a depth of $30 \mathrm{~cm}$ was observed. The presence of ${ }^{137} \mathrm{Cs}$ and ${ }^{241} \mathrm{Am}$ were noted in the area containing automorphous soils to a depth of $60 \mathrm{~cm}$. In addition, the upper soil layers at the test site were found to contain ${ }^{243} \mathrm{Am}$ and ${ }^{243} \mathrm{Cm}$. Over the past ten years, the ${ }^{241} \mathrm{Am} /{ }^{137} \mathrm{Cs}$ ratio in soil at the experimental site has increased by a factor of 3.4, nearly twice as much as would be predicted based solely on radioactive decay. This may be due to "fresh" fallout emanating from the ChNPP Confinement Shelter.
\end{abstract}

Key words: Chernobyl; radionuclide transport; fallout, migration 


\section{INTRODUCTION}

Studies of radionuclide behavior in the environment have been essential for both understanding mechanisms and pathways of radionuclide transport and assessment of radioecological hazards for the populations inhabiting contaminated areas. Studies of the behavior of transuranic radionuclides are especially significant due to the following factors:

1) Transuranic nuclei are, for the most part, alpha emitters, presenting an especially high radiobiological hazard; and

2) Little data are currently available on behavior of transuranic radionuclides in the Chernobyl Exclusion Zone environment.

These studies are important for the ChNPP accident zone as well because no valid data have been obtained to date on the location of over one third of the total mass of the fuel originating in the ChNPP $4^{\text {th }}$ Reactor Unit. A significant part of this fuel may be present in the fallout in the vicinity of the ChNPP $4^{\text {th }}$ Reactor Unit.

Some comprehensive studies have been performed on the behavior of radionuclides of Chernobyl origin in the environment, mainly focusing on ${ }^{238-240} \mathrm{Pu}$ and ${ }^{241} \mathrm{Am}$ isotopes (Bondarkov et al. 2006; Zheltonozhskaya 2009). While studying transuranic transport in the ChNPP proximity zone, one should keep in mind that, from the standpoint of terrain related factors for aqueous flow movement, seepage absolutely prevails over the surface flow. There are also various combinations of mechanical, sorption, and gley soil barriers present. Therefore, the forecast of rapid dissolution and transport of the radioactive fallout has been fairly optimistic.

Areas were selected in the most contaminated locations of the ChNPP 30-km zone where in 1986 a pinewood forest, called the Red Forest, died due to effects of the radioactive fallout. 
The spatial distribution of the radioactive fallout in the Red Forest experimental site is extremely heterogeneous. The average contamination density throughout the experimental site range as follows: $40-80 \mathrm{MBq} \mathrm{m}^{-2}$ for ${ }^{90} \mathrm{Sr}$ and $70-170 \mathrm{MBq} \mathrm{m}{ }^{-2}$ for ${ }^{137} \mathrm{Cs}$. The path of the radioactive fallout plume appears to have moved from the north-east to the south-west over the locations selected for the studies.

\section{METHODS AND RESULTS}

This paper presents results of vertical migration studies of Chernobyl origin isotopes in samples acquired in 2009. The samples were obtained from various soil layers up to $60 \mathrm{~cm}$ deep in the 5-km area throughout the Red Forest experimental site located within the $30-\mathrm{km}$ ChNPP Zone. Layer-by-layer samples were obtained at depths of: 0-2 cm, 2-4 cm, 4-7 cm, 7-10 cm, 10$15 \mathrm{~cm}, 15-20 \mathrm{~cm}, 20-25 \mathrm{~cm}, 25-30 \mathrm{~cm}, 30-35 \mathrm{~cm}, 35-40 \mathrm{~cm}, 40-45 \mathrm{~cm}, 45-50 \mathrm{~cm}, 50-55 \mathrm{~cm}$, and $55-60 \mathrm{~cm}$. The ${ }^{60} \mathrm{Co},{ }^{90} \mathrm{Sr},{ }^{137} \mathrm{Cs},{ }^{154,155} \mathrm{Eu}$, and ${ }^{241} \mathrm{Am}$ activities were measured in the samples using a gamma spectrometer.

All transuranic radionuclide migration studies in the ChNPP 5-km zone were performed using a non-radiochemical methodology developed by the authors at the International Radioecology Laboratory. This methodology measured both gamma spectra and x-ray emissions resulting from the internal conversion of gamma-ray transitions. This methodology made it possible to decrease systematic errors associated with radionuclide measurements in the soil samples of various thicknesses and mass and to determine the total alpha-activity of ${ }^{241} \mathrm{Am}$ and plutonium isotopes. To determine the total plutonium and ${ }^{241} \mathrm{Am}$ activity, the fact was relied on that, with a $25 \%$ probability, alpha-decay of plutonium isotopes excites a number of low-energy 
states of corresponding uranium isotopes with the energy lower than the energy of K-electron bonds. The energies of these states are 43.5, 51 , and $45 \mathrm{keV}$ and they are populated with alpha decays of ${ }^{238} \mathrm{Pu},{ }^{239} \mathrm{Pu}$, and ${ }^{240} \mathrm{Pu}$, respectively. The decay of these states is due to the internal conversion of the E2 multipolarity gamma-rays followed by emanation of characteristic x-ray emissions with the energies ranging from 13 to $23 \mathrm{keV}$. Fig. 1 shows a corresponding spectrum fragment of the Red Forest soil sample measured by the HPGe detector with a volume of $1 \mathrm{~cm}^{3}$, a beryllium window, and a resolution of $300 \mathrm{eV}$ for the $17 \mathrm{keV}$ line.

The high resolution of the detector and the processing of the experimental spectrum by "inserting" the instrument line measured by the same detector into the spectrum make it possible to unambiguously and accurately ( $\sim 5 \%$ uncertainty) divide the entire L-groups of neptunium corresponding to ${ }^{241} \mathrm{Am}$ decay and the L-groups of uranium corresponding to alpha-decay of plutonium isotopes (Fig. 2). Probabilities of population of low-energy states and coefficients of $\mathrm{x}$-ray fluorescence yield are well-known. Using calibration sources, the yield of $\mathrm{L}_{\beta}$ and $\mathrm{L}_{\alpha}$ groups from plutonium isotopes of the Chernobyl origin can also be directly measured. Our measurements show that the corresponding $x$-ray intensities per disintegration (\%) are as follows:

$$
\begin{aligned}
& \mathrm{I}\left(\mathrm{L}_{\beta}\right)=5.2 \pm 0.2 \\
& \mathrm{I}\left(\mathrm{L}_{\alpha}\right)=3.9 \pm 0.2
\end{aligned}
$$

Therefore, if the $\mathrm{x}$-ray intensity is measured, the plutonium content in the soil samples can easily be determined. The measured sample should be kept fairly thin to avoid selfabsorption of the x-ray emissions in the sample. However, using thin samples and high- 
resolution detectors with an apparent low effectiveness for gamma-radiation registration requires a longer time for measurements. If a large quantity of similar type samples has to be measured, the following two factors can make this method run faster.

First, fairly thick samples can be used. To be able to adequately take into account selfabsorption of soft x-ray emission in the sample, the following fact should be considered. In most cases, Chernobyl samples contain a significant amount of ${ }^{137} \mathrm{Cs}$. The ${ }^{137} \mathrm{Cs}$ decay excites an isomeric state of $661 \mathrm{keV}^{137} \mathrm{Ba}$ followed by emission of characteristic $\mathrm{Kx}$-irradiation of barium $\left(E_{\mathrm{Kx}}=32-37 \mathrm{keV}\right)$. The self-absorption coefficient for uranium Lx-emission can be calculated using the intensity of the x-ray $\mathrm{Kx}$-emission of barium and an associated harder $661 \mathrm{keV}$ gamma-emission, for which self-absorption is not essential. The obtained self-absorption coefficient is used to determine the plutonium isotopes content based on the measurements of intensity of the $\mathrm{x}$-ray $\mathrm{L}_{\mathrm{x}}$-emission of uranium.

Second, larger volume detectors can be used. Fig. 3 shows a spectrum fragment for the same Red Forest soil sample as shown in Fig. 2 but measured by an HPGe detector with a volume of $150 \mathrm{~cm}^{3}$. Obviously, a lower resolution does not make it possible to divide $\mathrm{L}_{\beta}$ and $\mathrm{L}_{\alpha}$ groups that correspond to plutonium and americium decays. However, since the neptunium x-ray emission intensity associated with ${ }^{241} \mathrm{Am}$ decay and ${ }^{241} \mathrm{Am} 59 \mathrm{keV}$ gamma-line ratio does not depend on the detector, but it is characteristic of the isotope decay, this ratio can be measured just once with a good accuracy using a high resolution detector (defined as the calibration ratio) and then the calibration ratio can be applied to any detector. In this regard, the contribution of, for example, $\mathrm{L}_{\beta}$-group associated with americium decay, $\mathrm{I}\left(\mathrm{L}_{\beta}\right)_{\mathrm{Am}}$, into the total non-resolved $\mathrm{x}$ ray peak of americium and plutonium (Fig. 3), can easily be calculated using the ratio:

$$
\mathrm{I}\left(\mathrm{L}_{\beta}\right)_{\mathrm{Am}}=1(\gamma 59) \times 1\left(\mathrm{~L}_{\beta}\right)_{\text {calibr }} / 1(\gamma 59)_{\text {calibr }}
$$


where $\mathrm{I}\left(\mathrm{L}_{\beta}\right)_{\text {calibr }} / \mathrm{I}(\gamma 59)_{\text {calibr }}$ is the ratio of $\mathrm{L}_{\beta}$ group intensities and $59 \mathrm{keV}$ gamma-line measured using the calibration detector; $\mathrm{I}(\gamma 59)$ is the $59 \mathrm{keV}$ gamma-line intensity measured by a large volume detector. Deducting the contribution of $\mathrm{L}_{\mathrm{x}}$-emission associated with americium decay from the total $\mathrm{I}\left(\mathrm{L}_{\beta}\right)_{\mathrm{U}, \mathrm{Np}}$ peak, the $\left.\mathrm{I}\left(\mathrm{L}_{\beta}\right)\right)_{\mathrm{U}}$ intensity associated with the decay of alpha-emitting plutonium isotopes is obtained. Taking into account the $\mathrm{L}_{\beta} \mathrm{U}$ (1) yield, the total ${ }^{238-240} \mathrm{Pu}$ activity in the measured sample is obtained. The accuracy of the proposed method is $10-15 \%$ for activities over $100 \mathrm{~Bq}$ and $20-30 \%$ for activities below $100 \mathrm{~Bq}$. The sensitivity of the method is 3 - $4 \mathrm{~Bq}$ for the Red Forest soil. It should be noted that measurements using a large detector mandate the presence of commeasurable alpha-activities of plutonium and americium.

To verify the proposed method, the total ${ }^{238-240} \mathrm{Pu}$ alpha-activity was measured in 24 samples of the Red Forest soil using standard radiochemical methods with ${ }^{242} \mathrm{Pu}$ tracers. These soil samples were taken from the surface and up to $30 \mathrm{~cm}$ deep layers. Fig. 4 shows a correlation of the ${ }^{238-240} \mathrm{Pu}$ content measurements in the Red Forest soil samples obtained by both methods and Table 1 provides the same results in a numerical form, with both showing a very good consistency in the data. It should also be noted that the mass of the soil samples ranged from about $10 \mathrm{~g}$ up to $170 \mathrm{~g}$.

The gamma spectra of the radionuclides also were analyzed using an anti-Compton spectrometer with a HPGe detector, beryllium window and the power resolution of $1.9 \mathrm{keV}$ for ${ }^{60} \mathrm{Co}$ gamma lines and $350 \mathrm{eV}$ for the $59 \mathrm{keV}$ gamma from ${ }^{241} \mathrm{Am}$. The spectrometer effectiveness was $30 \%$, in comparison with the $7.6 \mathrm{~cm} \times 7.6 \mathrm{~cm} \mathrm{NaI(Tl)}$ detector. The suppression of the Compton background at low energies was at least a factor of eight, making it possible to reliably identify the ${ }^{241}$ Am activity even in the deepest layers (Fig. 5). 
The obtained activity values were utilized to calculate isotopic ratios for five soil layers. The analysis of the obtained isotopic ratios and their comparison with the previously obtained data (Ivanov and Kashparov 1992) showed that the sampled areas had been contaminated with the fuel component of the fallout. Table 2 contains activities of the major gamma radionuclides typical for this type of contamination.

\section{DATA ANALYSIS AND CONCLUSIONS}

In these studies, the velocity of vertical migration of plutonium isotopes was similar to the velocity of ${ }^{241}$ Am vertical migration. However, the second layer demonstrated the plutonium isotopes velocity of vertical migration to be $15-20 \%$ lower than that of ${ }^{241} \mathrm{Am}$. In the third and the fourth layers, the difference decreased to $10-15 \%$, and, starting from the $15 \mathrm{~cm}$ deep layer, the velocity of plutonium and ${ }^{241}$ Am vertical migrations were practically the same (within the measurements uncertainties limits). Therefore, for subsequent analysis, ${ }^{241} \mathrm{Am}$ data was used since the measurements uncertainty for ${ }^{241} \mathrm{Am}$ activity concentration did not exceed 5\% even for $50-60 \mathrm{~cm}$ deep soil layers.

Figs. 6-8 show the obtained data on the radionuclide redistribution in selected soil layers of the Red Forest experimental site. For comparison, locations with the maximum and minimum transport velocities were selected. Fig. 6 shows the data on the ${ }^{241}$ Am distribution in the soil profile, in comparison with cesium and europium distribution, analyzed in 1999 and 2009. Fig. 7 shows ${ }^{241} \mathrm{Am}$ distribution in the soil profile in various locations of the experimental site (2009 data). It appears that the transport velocity practically has not changed, relative to the data obtained 10 years ago. This fact indicates that the vertical migration parameters obtained using the convective and diffusion transport model (Ivanov et al.1992, Ivanov 2009, Bondarkov et al. 
2006) also can be successfully used for current radioecological assessments. In the framework of this model the radionuclide transfer parameters in the soil profiles can be calculated by fitting the experimental data to the model distribution using the following equation:

$\mathrm{C}(\mathrm{x}, \mathrm{t})=\mathrm{C}_{0} \cdot\left\{\frac{1}{\sqrt{\pi \cdot \mathrm{D} \cdot \mathrm{t}}} \exp \left(-\frac{(x-V \cdot t)^{2}}{4 D \cdot t}\right)-\frac{V \cdot x}{2 D} \exp \left(-\frac{\mathrm{V} \cdot \mathrm{x}}{\mathrm{D}}\right)\left[1-\operatorname{erf}\left(\frac{\mathrm{x}+\mathrm{V} \cdot \mathrm{t}}{2 \sqrt{\mathrm{D} \cdot \mathrm{t}}}\right)\right]\right\}$

where $\mathrm{C}_{0}$ is the initial soil layer concentration, $\mathrm{C}(\mathrm{x}, \mathrm{t})$ is the radionuclide content in the $\mathrm{x}$ soil layer at time $\mathrm{t}$; $\mathrm{D}$ is the diffusion coefficient for the radionuclide $\left(\mathrm{cm}^{2} \cdot \mathrm{y}^{-1}\right)$; $\mathrm{V}$ is the velocity of the radionuclide directional transfer with a moisture flow $\left(\mathrm{cm} \cdot \mathrm{y}^{-1}\right)$.

The measured ${ }^{241} \mathrm{Am} /{ }^{137} \mathrm{Cs}$ ratio in soil appears to be important indicator. In the year 2000, the average ${ }^{241} \mathrm{Am} /{ }^{137} \mathrm{Cs}$ ratio for the experimental site was as follows: ${ }^{241} \mathrm{Am} /{ }^{137} \mathrm{Cs}=$ $0.013 \pm 0.003$. Currently, this ratio for the sampled soil layers from the same experimental site is ${ }^{241} \mathrm{Am} /{ }^{137} \mathrm{Cs}=0.044 \pm 0.006$. Based on radioactive decay, the isotopic ratio of ${ }^{241} \mathrm{Am}$ and ${ }^{137} \mathrm{Cs}$ should have increased by a factor of 1.75 during this time period and theoretically should currently be equal to 0.022 . However, it has increased by a factor of 3.4. For comparison, the ${ }^{241} \mathrm{Am} /{ }^{137} \mathrm{Cs}$ ratio was considered for the "hot" particles sampled from the lava-like fuel containing materials of the ChNPP Confinement Shelter. These "hot" particles have the same burnup as in the "hot" particles sampled in the soil at the experimental site. This ratio was measured to be: ${ }^{241} \mathrm{Am} /{ }^{137} \mathrm{Cs}=0.074 \pm 0.005$.

One of the possible explanations of this fact is that, currently, an intense destruction of lava-like fuel-containing materials is in progress at the ChNPP $4^{\text {th }}$ Reactor Unit. Due to spontaneous dust generation in the Confinement Shelter, radioactive aerosols with particle sizes of $60-300 \mathrm{~nm}$ and activity equivalent to that of a few dozens of kilograms of spent nuclear fuel (SNF) have been accumulating there. These aerosols contain plutonium and americium in the 
same proportions as SNF. Their high inhalation effectiveness and capability to spread long distances present a serious radioecological hazard (Baryakhtar et al 1997). Therefore, it is assumed that, currently, up to $50 \%$ of the fallout in the vicinity of the ChNPP site may be associated with "fresh" fallout from the Confinement Shelter.

The obtained data made it possible to evaluate periods of environmental half-life for the upper 5-cm deep soil layer in the sampled experimental sites using the modified convective diffusion transport model. As in the previously completed studies (Bondarkov et al 2006), the ${ }^{241}$ Am environmental half-life in areas with maximum radionuclide transport equals to about 30 years, which is close to the ${ }^{137} \mathrm{Cs}$ environmental half-life in soils. However, it is by an order of magnitude lower in the areas with a slow radionuclide transport.

The conducted studies demonstrate intense processes of destruction of fuel particles that accelerate migration of transuranic radionuclides and ${ }^{90} \mathrm{Sr}$ in the environment. For the first time, the presence of ${ }^{241} \mathrm{Am}$ in all soil layers down to $60 \mathrm{~cm}$ deep was recorded with a high level of confidence. ${ }^{243} \mathrm{Am}$ and ${ }^{243} \mathrm{Cm}$ activities were observed in the gamma spectra of the upper soil layers; thereby, making it possible to assess behavior of these radionuclides in the environment.

Acknowledgments - The authors would like to thank Ines Triay, Yvette Collazo, Kurt Gerdes, and Ana Han for their support of the U.S. Department of Energy Office of Environmental Management's International Cooperative Program with IRL. The authors would also like to express their gratitude to Tatyana Albert (Thomas E. Albert and Associates, Inc.) for translating documents and reports prepared at SRNL and IRL and Elizabeth LaBone for editing this article. 
Disclaimer - This manuscript has been co-authored by Savannah River Nuclear Solutions, LLC under Contract No. DE-AC09-08SR22470 with the U.S. Department of Energy. The United States Government retains and the publisher, by accepting this article for publication, acknowledges that the United States Government retains a non-exclusive, paid-up, irrevocable, worldwide license to publish or reproduce the published form of this work, or allow others to do so, for United States Government purposes. Mention of trade names or commercial products does not constitute endorsement or recommendation for use by the authors or their corresponding organizations.

\section{REFERENCES}

Bondarkov MD, Gaschak SP, Zheltonozhskaya MV, Maksymenko AM, Martynenko VI, Rodgers B, Chesser R, Bonadrkov MD. Vertical migration of radionuclides in the areas of chernobyl test sites. Problems of Safety of Nuclear Power Plants and Chernobyl (6):155-163; 2006. (rus)

Zheltonozhskaya MV. Study of isotopic ratios in soil layers of the ChNPP 5-km zone. Nuclear Physics and Power Engineering 10(4):409-412; 2009. (rus)

Ivanov YuA, Kashparov VA. Behavior of radionuclides represented by the ChNPP accident fuel component in soils. Radiokhimiya Journal — 5:112-124: 1992. (rus)

Baryakhtar VG, Gonchar VV, Zhidkov AV, Kluchnikov AA. On dust generation capability of the ChNPP accident related spent fuel and lava-like fuel-containing materials of the confinement shelter. Preprint. National Academy of Sciences of Ukraine. Ukrytie Interdepartmental Scientific and Technical Center, Chernobyl 20: 97-110; 1997. (rus) 
Ivanov Yu.A., Kashparov VA., Levchuk SE. Vertical migration of ChNPP released radionuclides in soils. 1. Long-term dynamics of radionuclide redistribution in in-situ soil profiles//Radiochemistry Journal, 1996, vol.38, issue 3, pp. 264-271

Ivanov $\mathrm{Yu}$ A. Migration of fuel particles of CHNPP fallout and leached radionuclides in soils and soil-to-plant system. // Radioactive Particles in the Environment, D.H. Oughton and V.Kashparov (eds.), Springer Science +Business Media B.V. 2009. P.123-137 


\section{FIGURE CAPTIONS}

Fig. 1. Spectrum fragment for the Red Forest soil sample measured by $1 \mathrm{~cm}^{3}$ high purity Ge detector in the range 1-60 keV.

Fig. 2. Decomposition of a spectrum fragment on components for the Red Forest soil sample measured by $1 \mathrm{~cm}^{3} \mathrm{HPGe}$ detector.

Fig. 3. Spectrum fragment for the Red Forest soil sample measured by $150 \mathrm{~cm}^{3}$ volume HPGe detector.

Fig. 4. Comparison of results of measurements of ${ }^{238-240} \mathrm{Pu}$ activities in the soil samples using spectrometric and radiochemical methods.

Fig. 5. Fragments of gamma spectra in soil samples at various depths.

Fig. 6. Data on ${ }^{241} \mathrm{Am}$ distribution in soil profiles relatively to cesium and europium distribution a) 2009 data; b) 1999 data.

Fig. 7. ${ }^{241} \mathrm{Am}$ distribution in soil profiles in various locations of the test site, 2009 data (1 - area with the minimum transport velocity; 2 - area with the maximum transport velocity).

Fig. 8. Data on ${ }^{241} \mathrm{Am}$ distribution in the soil profile in comparison with ${ }^{137} \mathrm{Cs}$ in the area with the minimum transport velocity (2009). 


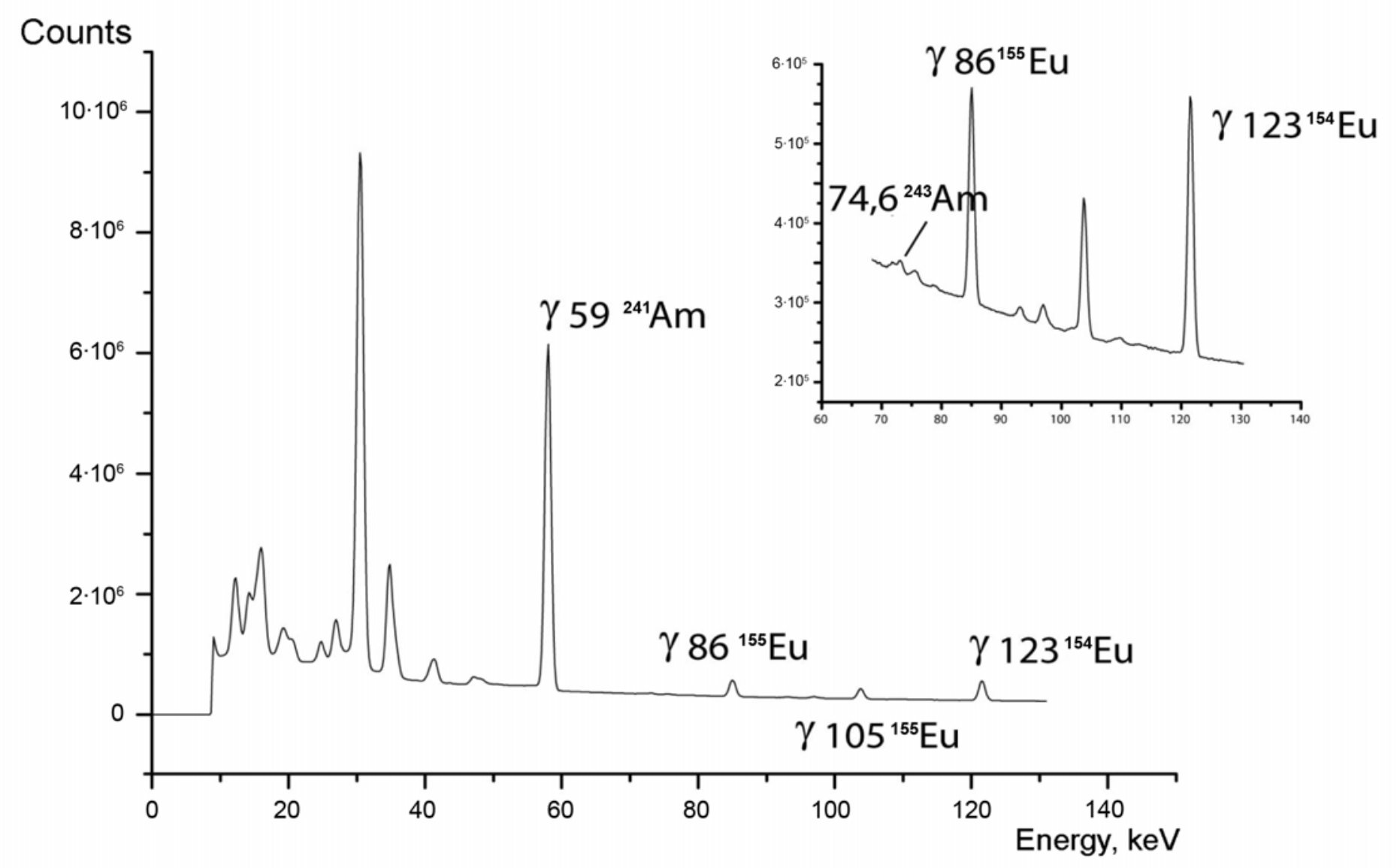

Fig. 1. Spectrum fragment for the Red Forest soil sample measured by $1 \mathrm{~cm}^{3}$ high purity Ge detector in the range 1-60 keV. 


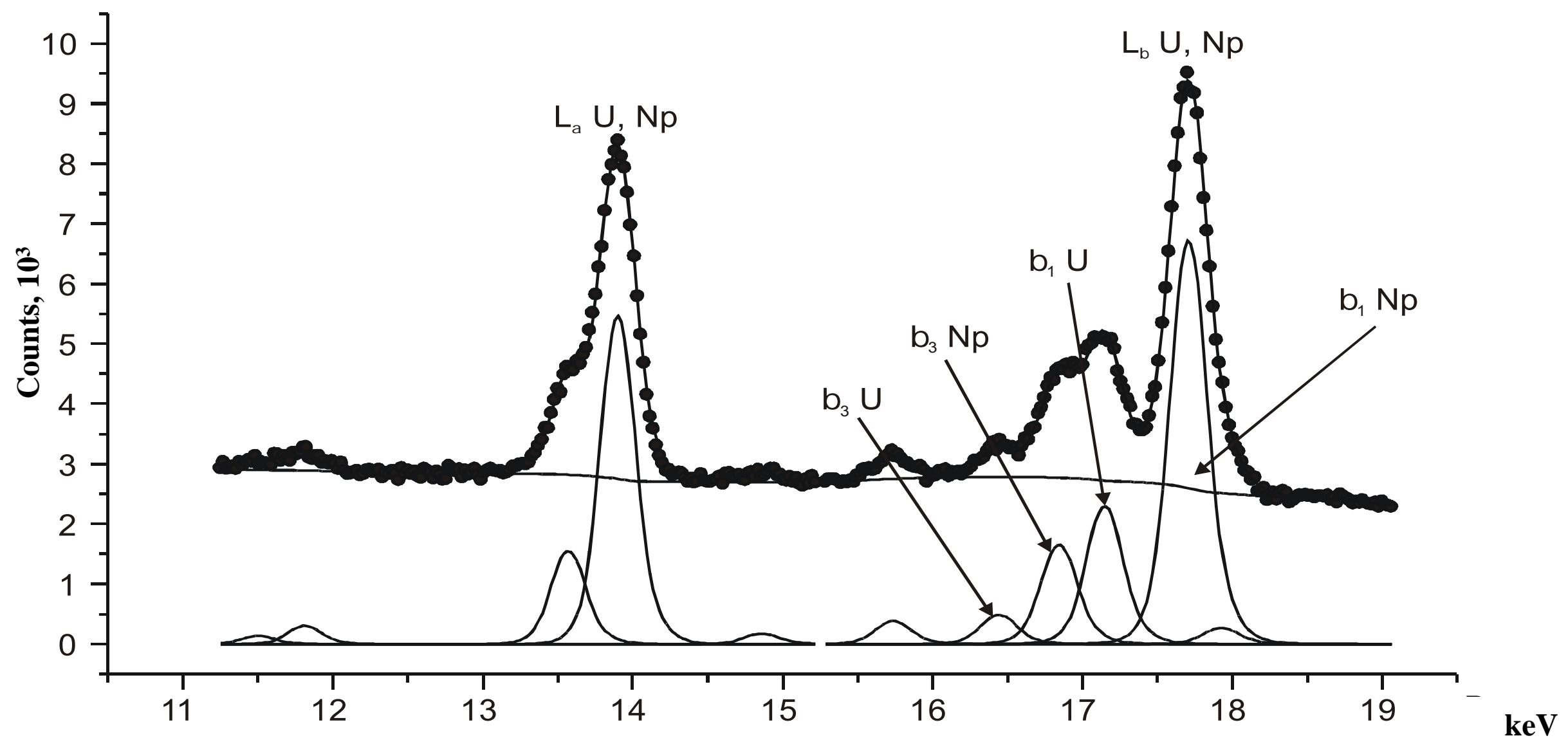

Fig. 2. Decomposition of a spectrum fragment on components for the Red Forest soil sample measured by $1 \mathrm{~cm}^{3} \mathrm{HPGe}$ detector. 


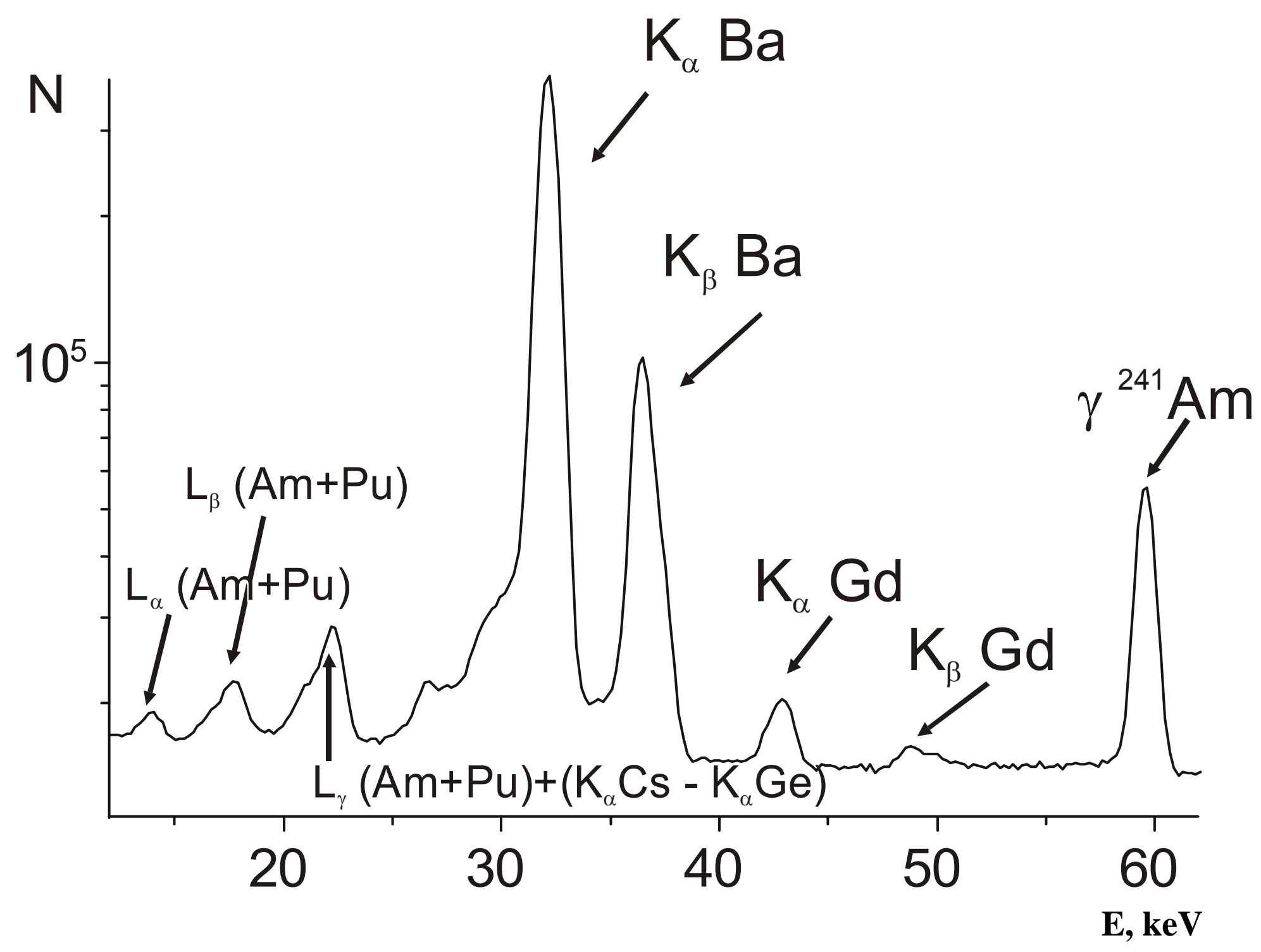

Fig. 3. Spectrum fragment for the Red Forest soil sample measured by $150 \mathrm{~cm}^{3}$ volume HPGe detector. 


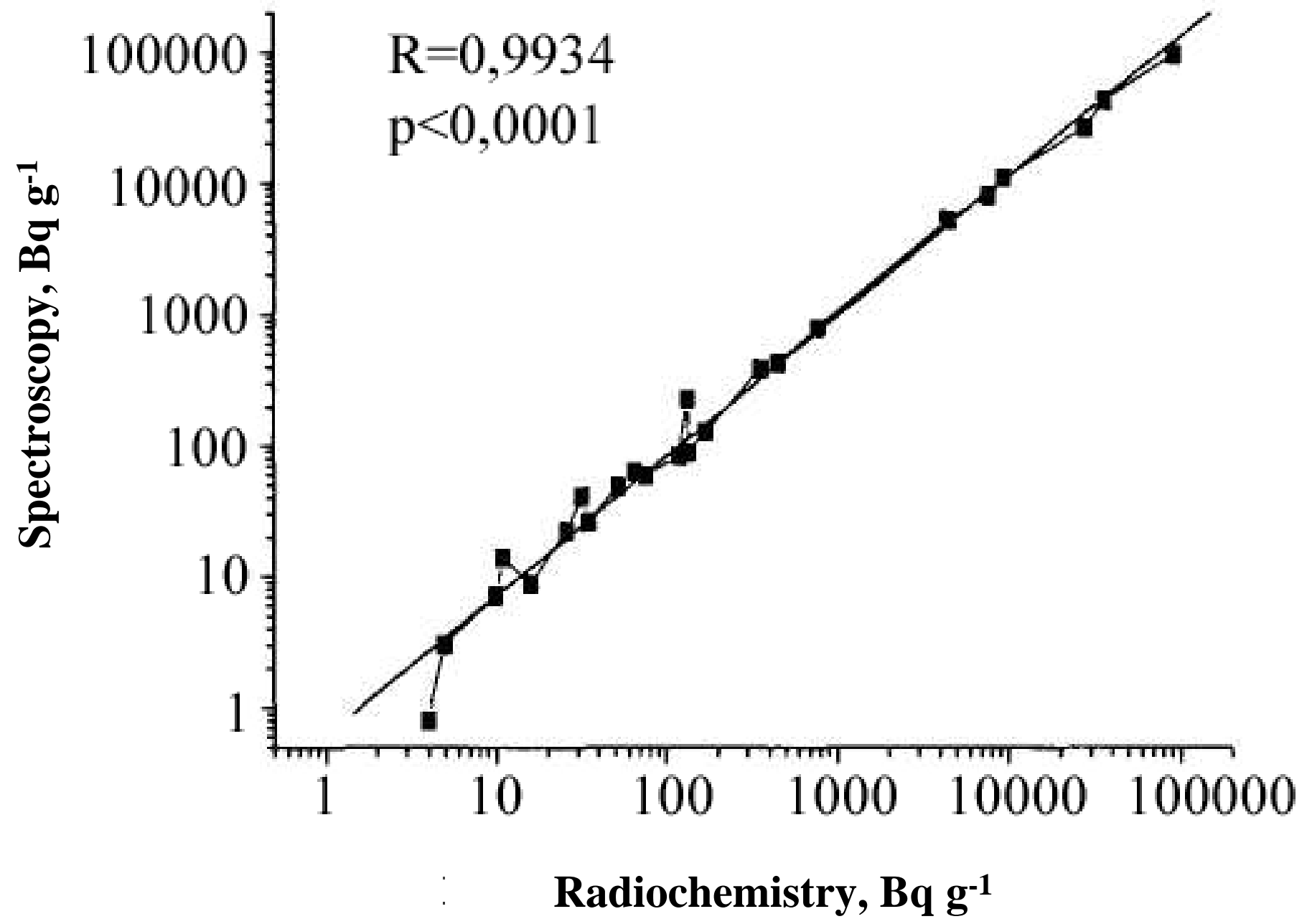

Fig. 4. Comparison of results of measurements of ${ }^{238-240} \mathrm{Pu}$ activities in the soil samples using spectrometric and radiochemical methods. 

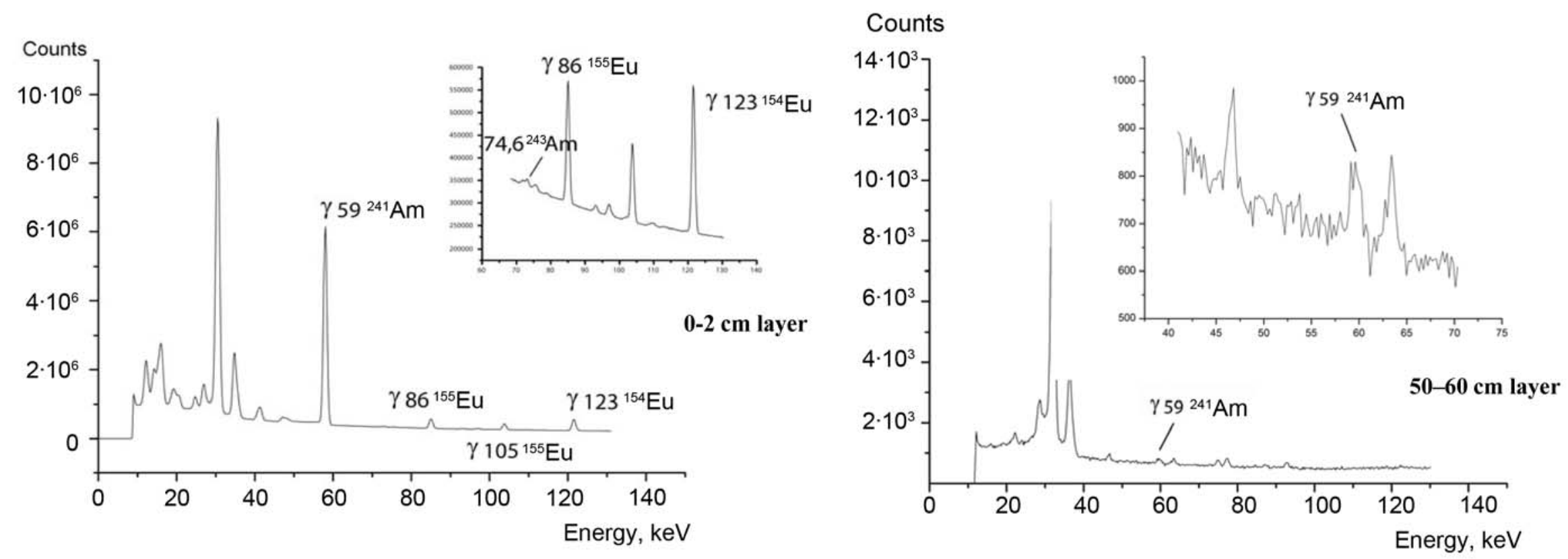

Fig. 5. Fragments of gamma spectra in soil samples at various depths. 


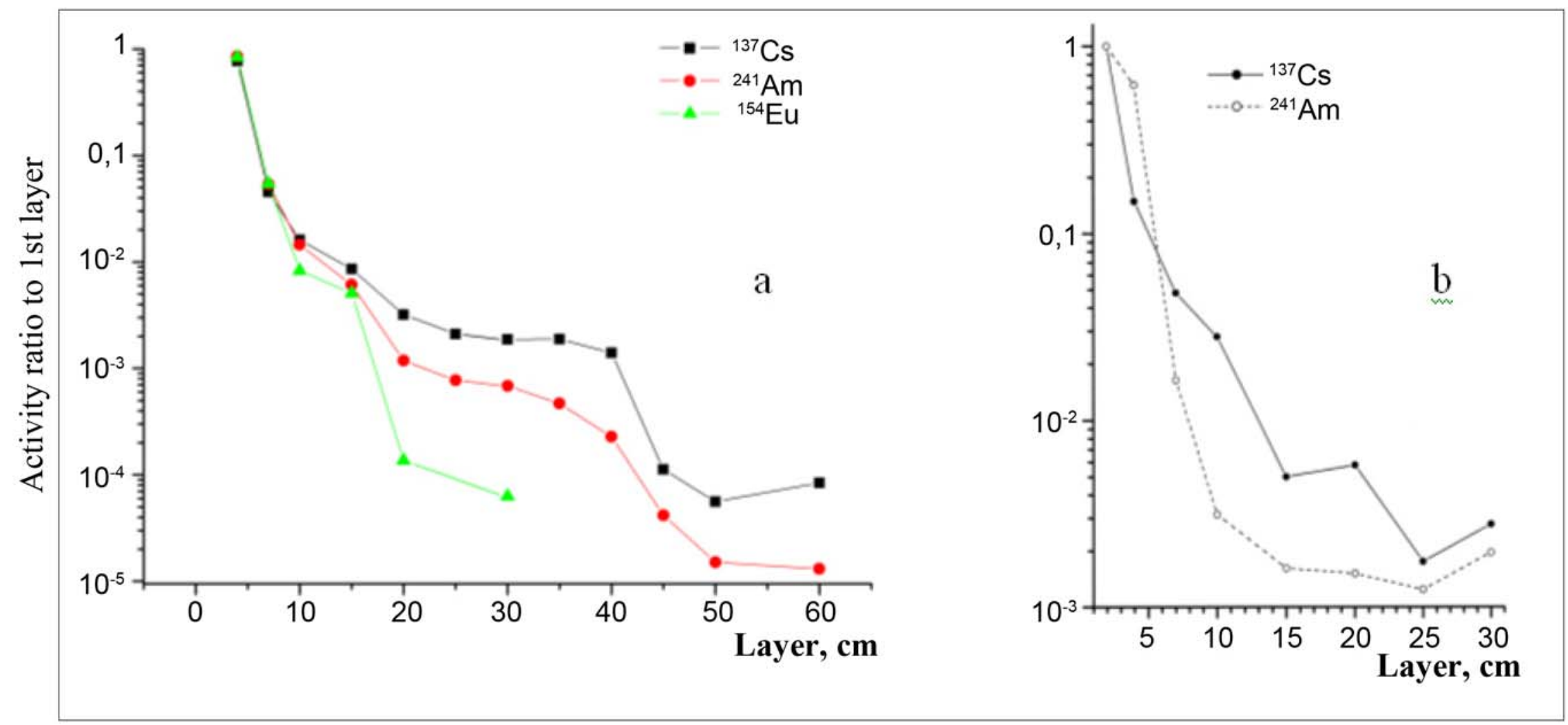

Fig. 6. Data on ${ }^{241} \mathrm{Am}$ distribution in soil profiles relatively to cesium and europium distribution a) 2009 data; b) 1999 data. 


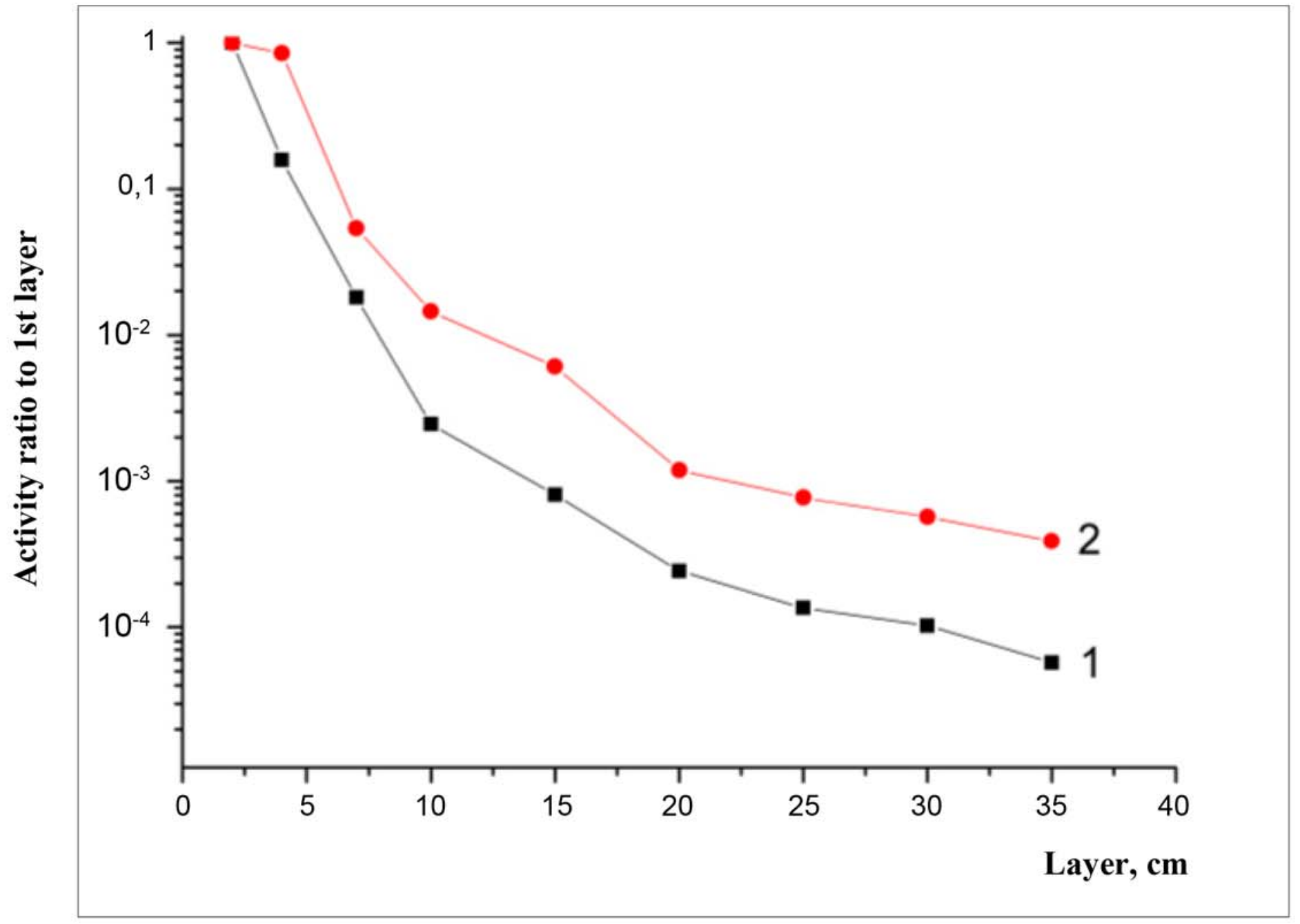

Fig. 7. ${ }^{241}$ Am distribution in soil profiles in various locations of the test site, 2009 data (1 - area with the minimum transport velocity; 2 - area with the maximum transport velocity). 


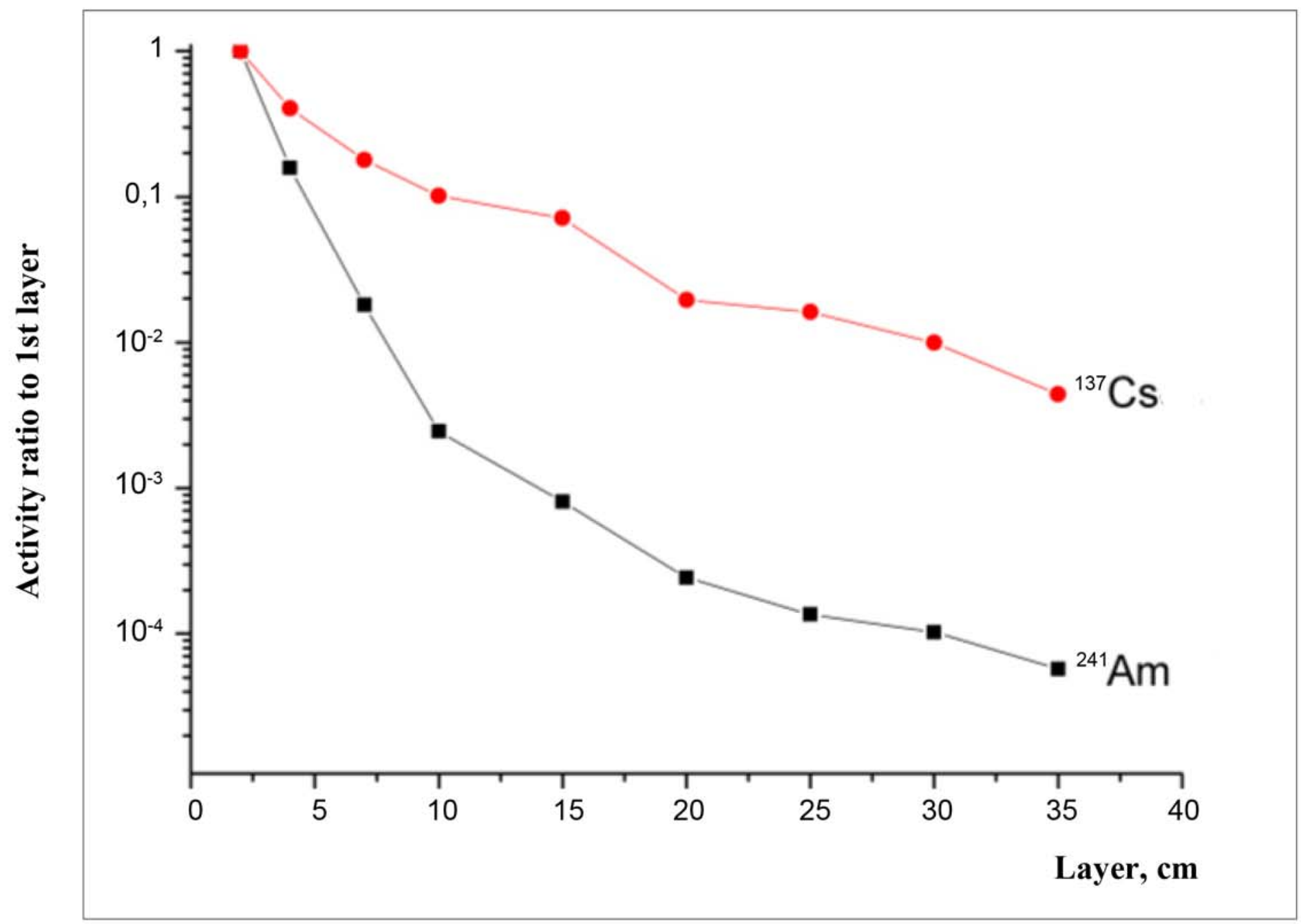

Fig. 8. Data on ${ }^{241} \mathrm{Am}$ distribution in the soil profile in comparison with ${ }^{137} \mathrm{Cs}$ in the area with the minimum transport velocity (2009). 
Table 1. Total alpha-activity of plutonium isotopes (Bq per sample).

\begin{tabular}{|c|c|c|c|c|}
\hline Sample & $\begin{array}{l}\text { Sample } \\
\text { mass, g }\end{array}$ & $\begin{array}{c}{ }^{238-240} \mathrm{Pu} \text { activity, } \\
\text { spectrometric method } \\
\text { (Aspectr) }\end{array}$ & $\begin{array}{l}{ }^{238-240} \text { Pu activity, } \\
\text { radiochemical method } \\
\text { (Aradiochemistry) }\end{array}$ & $\begin{array}{c}\text { (Aspectr - } \\
\text { Aradiochjemistry)/ } \\
\text { Aspectr }\end{array}$ \\
\hline $1-145-1$ & 22 & $28,400.0$ & $26,100.0$ & 0.08 \\
\hline $1-145-2$ & 26 & $7,870.0$ & $8,000.0$ & -0.02 \\
\hline $1-145-3$ & 35 & 462.0 & 430.0 & 0.07 \\
\hline $1-145-4$ & 32 & 136.0 & 89.0 & 0.35 \\
\hline $1-145-5$ & 114 & 26.0 & 22.4 & 0.14 \\
\hline $1-145-6$ & 121 & 16.0 & 8.8 & 0.45 \\
\hline $1-145-7$ & 145 & 5.0 & 3.0 & 0.40 \\
\hline $1-145-8$ & 162 & 4.0 & 0.8 & 0.81 \\
\hline $2-145-1$ & 13 & $37,000.0$ & $42,000.0$ & -0.14 \\
\hline $2-145-2$ & 19 & $9,650.0$ & $10,900.0$ & -0.13 \\
\hline $2-145-3$ & 29 & 364.0 & 390.0 & -0.07 \\
\hline $2-145-4$ & 38 & 172.0 & 128.0 & 0.26 \\
\hline $2-145-5$ & 149 & 52.2 & 49.0 & 0.06 \\
\hline $2-145-6$ & 158 & 32.0 & 41.0 & -0.28 \\
\hline $2-145-7$ & 138 & 65.0 & 63.0 & 0.03 \\
\hline $2-145-8$ & 125 & 76.0 & 59.0 & 0.22 \\
\hline $3-145-1$ & 8 & $93,200.0$ & $96,000.0$ & -0.03 \\
\hline $3-145-2$ & 19 & $4,560.0$ & $5,200.0$ & -0.14 \\
\hline $3-145-3$ & 20 & 787.0 & 790.0 & 0.00 \\
\hline $3-145-4$ & 17 & 135.0 & 229.0 & -0.70 \\
\hline $3-145-5$ & 126 & 120.0 & 84.0 & 0.30 \\
\hline $3-145-6$ & 131 & 35.0 & 26.0 & 0.26 \\
\hline $3-145-7$ & 167 & 11.0 & 13.9 & -0.26 \\
\hline $3-145-8$ & 160 & 10.0 & 7.1 & 0.29 \\
\hline
\end{tabular}


Table 2. Activities of isotopes of Chernobyl origin in the soil upper layer.

\begin{tabular}{cc}
\hline Radionuclide & Activity $\left(\mathrm{Bq} \mathrm{g}^{-1}\right)$ \\
\hline All Pu isotopes & 21.0 \\
${ }^{243} \mathrm{Am}$ & 0.040 \\
${ }^{243} \mathrm{Cm}$ & 0.046 \\
${ }^{137} \mathrm{Cs}$ & 498 \\
${ }^{134} \mathrm{Cs}$ & 0.104 \\
${ }^{154} \mathrm{Eu}$ & 5.0 \\
${ }^{155} \mathrm{Eu}$ & 1.47 \\
${ }^{60} \mathrm{Co}$ & 0.0059 \\
\hline
\end{tabular}

